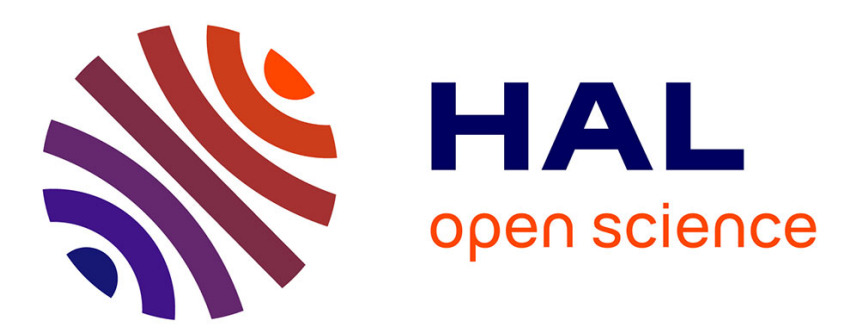

\title{
Experimental study and modelling of the tip-leakage flow for an isolated fixed blade
}

Benjamin Deveaux, Camille Fournis, Vincent Brion, Julien Marty, Antoine Dazin

\section{- To cite this version:}

Benjamin Deveaux, Camille Fournis, Vincent Brion, Julien Marty, Antoine Dazin. Experimental study and modelling of the tip-leakage flow for an isolated fixed blade. ASME-JSME-KSME Joint Fluids Engineering Conference, Jul 2019, SAN FRANCISCO, United States. hal-02339539

\section{HAL Id: hal-02339539 \\ https://hal.science/hal-02339539}

Submitted on 30 Oct 2019

HAL is a multi-disciplinary open access archive for the deposit and dissemination of scientific research documents, whether they are published or not. The documents may come from teaching and research institutions in France or abroad, or from public or private research centers.
L'archive ouverte pluridisciplinaire HAL, est destinée au dépôt et à la diffusion de documents scientifiques de niveau recherche, publiés ou non, émanant des établissements d'enseignement et de recherche français ou étrangers, des laboratoires publics ou privés. 


\title{
EXPERIMENTAL STUDY AND MODELLING OF THE TIP-LEAKAGE FLOW FOR AN ISOLATED FIXED BLADE
}

\author{
B. Deveaux, C. Fournis, V. Brion, J. Marty \\ ONERA, Meudon, France
}

\author{
A. Dazin \\ LMFL Kampe de Feriet, Lille, France
}

\begin{abstract}
The tip-leakage flow has detrimental effects on the performance of compressors. In this paper the effects of gap height and incoming casing boundary layer thickness are analyzed. Velocity and total pressure measurements are carried out in a plane behind the trailing edge of an isolated fixed blade. The total pressure loss is decomposed in a vortex loss and a wake loss. It appears that the increase of total pressure losses with the gap height comes essentially from the vortex part. This observation motivated the development of a model based on an analogy with a jet in crossflow to estimate the tip-leakage vortex circulation. The predictions of this model are consistent with the experimental data for gaps smaller than $4 \%$ of chord.
\end{abstract}

\section{NOMENCLATURE}

$\alpha \quad$ Angle of attack

$c$ Blade chord

$h$ Gap height

$U_{\infty} \quad$ Upstream velocity

$R e=U_{\infty} c / v \quad$ Chord Reynolds number

$M$ Mach number

$T_{U \infty} \quad$ Free stream turbulence intensity

$u_{i} \quad$ Mean velocity

$P$ Pressure

$T$ Temperature

$\rho$ Density

$s$ Entropy

$\Gamma \quad$ Tip-leakage vortex circulation

$\left(y_{v}, z_{v}\right) \quad$ Vortex center position

$\delta_{0.99} 0.99 U_{\text {max }}$ thickness $\delta^{*} \quad$ Displacement thickness

$\theta^{*} \quad$ Momentum thickness

$H^{*}=\delta^{*} / \theta^{*} \quad$ Shape factor

$\operatorname{Re}_{\theta^{*}}=U_{\infty} \theta^{*} / v \quad$ Momentum thickness Reynolds number

$\chi_{D} \quad$ Discharge coefficient

$U_{j} \quad$ Gap exit jet velocity

$C_{L} \quad$ Airfoil lift coefficient

$C_{P t}=\left(P_{t \infty}-P_{t}\right) /\left(\frac{1}{2} \rho U_{\infty}^{2}\right) \quad$ Losses coefficient

$C_{\text {wake }}=1-u_{x}^{2} / U_{\infty}^{2} \quad$ Wake losses

$C_{\text {vortex }}=C_{P t}-C_{\text {wake }}$ Vortex losses

$K_{P}=\left(P_{s}-P_{s \infty}\right) /\left(\frac{1}{2} \rho U_{\infty}^{2}\right) \quad$ Wall pressure coefficient

$\bullet_{\infty} \quad$ Upstream quantity

- $t \quad$ Total quantity

- $s$ Static quantity

- Pressure side quantity

- $\quad$ Suction side quantity

${ }^{m} \quad$ Mass-flow average

\section{INTRODUCTION}

The space between the blade tip and the casing wall of an axial flow compressor is often referred as tip-gap or tipclearance. The aerodynamic loading of the blade generates a leakage flow through that gap. This flow not only limits the compressors pressure rise and efficiency, but is also associated with the arising of compressor rotating stall and fan broadband noise.

Downstream of the blade the total pressure losses come primarily from the tip-leakage vortex $[1,2]$. Moreover this vortex exhibits a large streamwise velocity deficit for small gaps in its core that drives the production of turbulent kinetic energy [3]. 
Many studies show that a larger gap height increases the tip-leakage flow losses $[1,4,5]$. A bigger gap height leads to a smaller pressure rise, efficiency and operating range of the compressor [6].

The effect of the casing boundary layer thickness on the tip-leakage flow has been rarely studied. Storer and Cumpsty [5] have shown that a thicker boundary layer on the casing increased the total pressure loss coefficient without changing its evolution with the gap height.

Several models have been tried to describe the tipleakage flow losses in the past such as the lifting-line theory and the model of a jet.

In the former case, Lakshminarayana and Horlock [7] adopted the lifting-line theory to describe the flow through a slotted wing. They observed that, for small gaps, the theory overestimated the induced-drag as it had been noticed earlier by Flachsbart [4].

In the latter case, for small gaps, Denton [8] and then Storer and Cumpsty [5] adopted an alternative approach which consists in modelling the tip-leakage flow as a jet in crossflow in order to investigate the total pressure losses.

The first objective of this paper is to analyze the effects of gap height and casing boundary layer thickness on the tip-leakage flow. To do so an experimental parametric study is realized in a low-speed wind tunnel.

The second objective of this paper is to model the tipleakage flow as a jet in crossflow to have an estimation of the tip-leakage vortex circulation. The domain of validity of such an approach is evaluated based on the parametric study. In addition to that, the experimental data provides informations on the influence of the tip-leakage circulation on the evolution of the total pressure losses.

\section{DESCRIPTION OF THE EXPERIMENT}

\subsection{SETUP}

Experiments were conducted in the low-speed wind tunnel S2L located at the ONERA center of Meudon. The setup is placed in a wooden test section represented in figure 1. This test section has a length of $1.75 \mathrm{~m}$.

As displayed in figure 2, a NACA0012 straight blade with a chord $c=200 \mathrm{~mm}$ is placed perpendicular to a flat plate which models the casing. The distance between the casing and the upper wall of the wind tunnel remains fixed at $560 \mathrm{~mm}$. The blade leading edge is located $660 \mathrm{~mm}$ downstream the test section inlet.

This setup can reproduce values of $h / c$ encountered in real compressors and, as shown in table 2, larger gaps are possible. The gap is adjusted using gauge blocks placed at the leading edge of the blade. At the trailing edge, the gap is slightly bigger $(+0.1 \%$ of chord).

The boundary layer thickness upstream of the blade can be adjusted with the distance $L$ between the leading edges of the casing and the blade. This is done by adding or subtracting flat plate sections in front of the blade. In this study we consider $L / c=1.8$ and $L / c=3.3$.
The angle of attack $\alpha$ can be adjusted from $-15^{\circ}$ to $15^{\circ}$. Geometrical constraints imposed $\alpha<0$ to have measurements in the tip-leakage vortex. Thus the angle of attack $\alpha$ is fixed at $-10^{\circ}$, which provides a high aerodynamic loading.

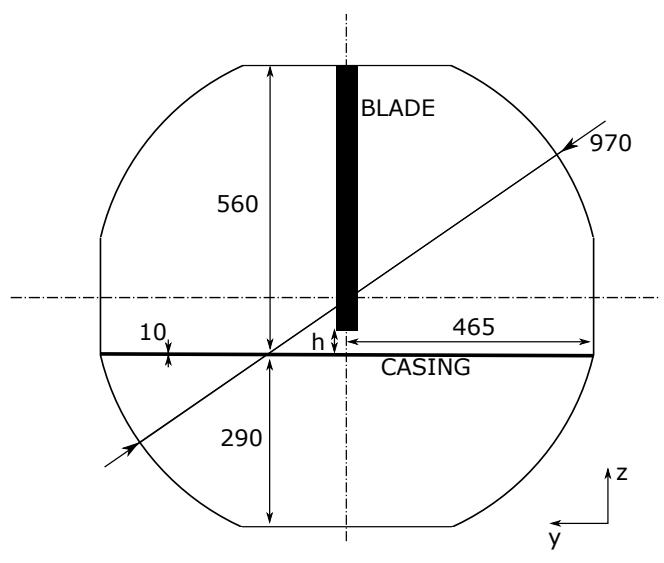

Fig. 1: Dimensions of the test section in millimeters

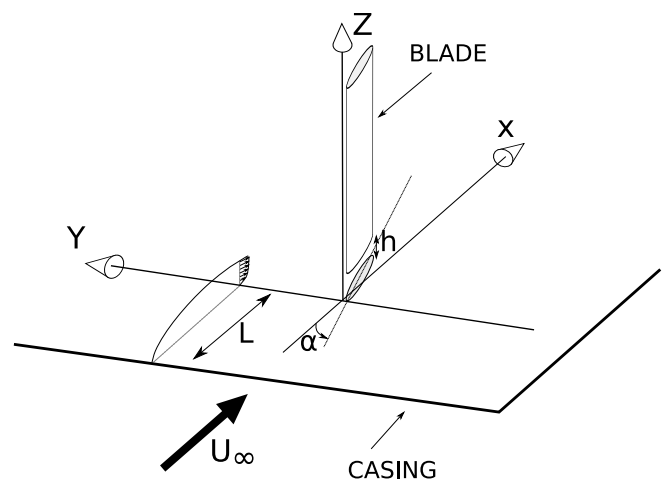

Fig. 2: Schematic view of the isolated fixed blade setup

\subsection{COORDINATE SYSTEM}

As illustrated in figure 2, the $x$ axis is oriented in the streamwise direction and the $z$ axis is perpendicular to the casing pointing upwards. The origin $(x, y)=(0,0)$ is defined as the leading edge of the blade at zero angle of attack $\left(\alpha=0^{\circ}\right)$ and $z=0$ corresponds to the casing wall.

\subsection{5-HOLE PRESSURE PROBE MEASURE- MENTS}

As shown in figure 3, velocity and total pressure measurements were realized behind the blade trailing edge with a 5-hole probe. This probe has a diameter of $1.6 \mathrm{~mm}$ and the uncertainties associated with the calibration method are \pm 0.001 for the Mach number and $\pm 0.15^{\circ}$ for pitch and yaw 
Table 2: Experimental parameters

\begin{tabular}{ll}
\hline \hline$U_{\infty}$ & $40 \mathrm{~m} / \mathrm{s}$ \\
$R e$ & 550000 \\
$M$ & 0.1 \\
$T_{U \infty}$ & $0.07 \%$ \\
Airfoil & NACA0012 \\
Blade rotation axis & $x=0.25 \mathrm{c}, y=0$ \\
$c$ & $200 \mathrm{~mm}$ \\
$\alpha$ & $-10^{\circ}$ \\
$h / c$ & $0.5 \%$ to $13 \%$ \\
$L / c$ & 1.8 or 3.3 \\
\hline \hline
\end{tabular}

angles. Moreover the uncertainty on the total pressure loss coefficient $C_{P t}$ is \pm 0.01 .

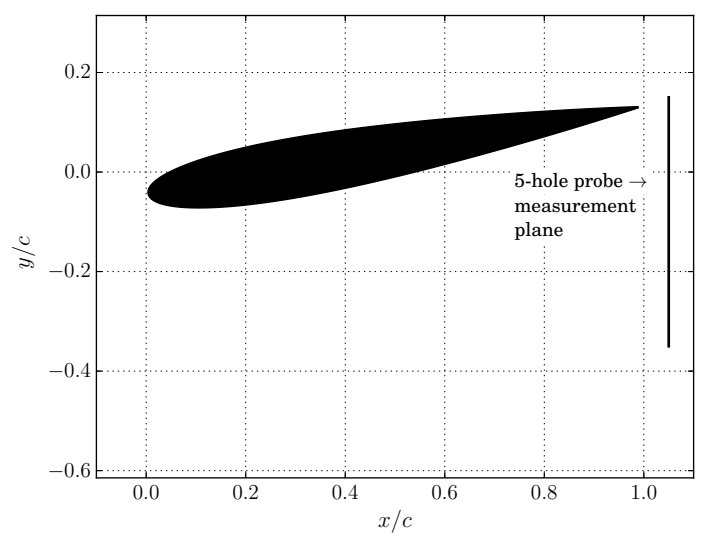

Fig. 3: Measurement plane at $x / c=1.05($ mesh resolution: $\Delta y \approx 2 \mathrm{~mm}$ and $\Delta z \approx 1 \mathrm{~mm}$ )

\section{FLOW CONDITIONS}

\subsection{FREE STREAM}

For this experiment, the Reynolds number is fixed at 550000 . As exposed in table 2, this corresponds to a Mach number of 0.1 , therefore the flow can be regarded as incompressible. The free stream turbulence intensity $T_{U \infty}$, which is measured with a hot wire $1.5 c$ upstream the blade, is about $0.07 \%$.

\subsection{CASING BOUNDARY LAYER}

A two-component laser doppler velocimetry is used to measure the evolution of the boundary layer on the casing. To mitigate the potential effect of the blade on the boundary layer, the gap height is adjusted to its maximum value

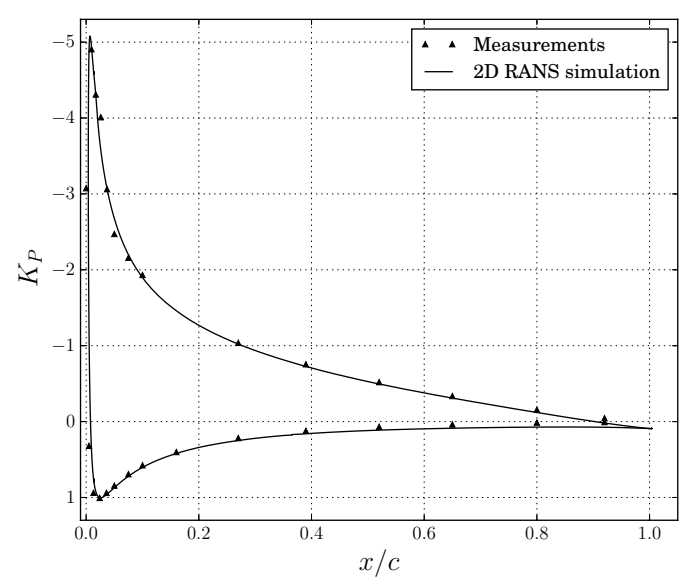

Fig. 4: Pressure distribution around the NACA0012 airfoil for $\alpha=-10^{\circ}(h=0)$. Pressure taps located in $z=1.7 c$

( $h=26 \mathrm{~mm}$ or $h / c=13 \%$ ) and the angle of attack is set to $0^{\circ}$. The properties of the boundary layer on the casing are synthetized in table 4 .

\subsection{BLADE PRESSURE DISTRIBUTION}

The steady flow around the two-dimensional NACA0012 airfoil is simulated with the finite volume code elsA. The convection flux is discretized with a second order AUSM+(P) scheme [9]. The fully turbulent $k-\omega-S S T$ model of Menter [10] is used in this computation.

The pressure distribution around the airfoil obtained in the simulation is compared to the measurements in figure 4. There is a good agreement between the simulation and the measurements.

\subsection{TRANSITION}

On the blade suction side the transition from laminar to turbulent flow arises from a laminar separation bubble located between $x / c=2 \%$ and $x / c=4 \%$.

On the pressure side the transition is triggered with a $125 \mu \mathrm{m}$ thick turbulator tape placed at $20 \%$ of chord from the leading edge.

On the casing wall, the same type of turbulator tape is placed $7.5 \%$ of chord downstream its leading edge.

\section{IDENTIFICATION OF THE TIP-LEAKAGE FLOW REGIMES}

The distance between the vortex center and the casing is represented in figure 5. The boundary layer thickness does not have a major effect on the vortex vertical position except for $h / c=0.5 \%$.

If the blade tip is far enough from the casing, the tip-leakage vortex should be similar to a wing-tip vortex. Therefore the position of the vortex relative to the blade 
Table 4: Boundary layer characteristics at $\boldsymbol{x}=0$

\begin{tabular}{llll}
\hline \hline$L / c$ & & 1.8 & 3.3 \\
\hline$\delta_{0.99}$ & $\left(\delta_{0.99} / c\right)$ & $7.02 \mathrm{~mm}(3.50 \%)$ & $11.44 \mathrm{~mm}(5.70 \%)$ \\
$\delta^{*}$ & $\left(\delta^{*} / c\right)$ & $1.09 \mathrm{~mm}(0.55 \%)$ & $1.82 \mathrm{~mm}(0.90 \%)$ \\
$\theta^{*}$ & $\left(\theta^{*} / c\right)$ & $0.82 \mathrm{~mm}(0.40 \%)$ & $1.35 \mathrm{~mm}(0.70 \%)$ \\
$H^{*}$ & 1.33 & 1.35 \\
$\operatorname{Re}_{\theta^{*}}$ & 2200 & 3600 \\
\hline \hline
\end{tabular}

tip should not vary anymore. As a consequence, for large gaps $z_{v}$ should vary like $h / c$, which seems to be the case for $h / c>8 \%$. For gap heights smaller than $4.5 \%$, the tip-leakage vortex vertical position seems to increase like $(h / c)^{0.372}$.

In other words the tip-leakage flow seems to have three different regimes depending on the gap height: a small gap regime for $h / c<4.5 \%$, a large gap regime for $h / c>8 \%$ and an intermediate regime in-between.

In the small gap regime at $x / c=1.05$, as shown in figure 6 , the tip-leakage vortex remains around $y / c=-0.11$. For larger gaps the vortex gets closer to the blade when the gap height is increased.

Increasing the casing boundary layer thickness moves the tip-leakage vortex away from the blade. This trend can be explained by doing an analogy with a jet in crossflow.

In fact increasing the boundary layer thickness reduces the average velocity $U_{0}$ of the main stream at the gap exit. Moreover based on Rains approach [11], the gap exit velocity $U_{j}$ depends primarily on the pressure difference between the pressure side and suction side of the blade. Thus the casing boundary layer thickness should have little impact on $U_{j}$. As a consequence increasing the boundary layer thickness increases the ratio $R=U_{j}^{2} / U_{0}^{2}$ which, as explained by Fearn and Weston [12], extends the penetration of the jet in the crossflow, hence a larger distance between the tip-leakage vortex and the blade.

In summary, in the small gap regime the tip-leakage flow has similarities with a jet in crossflow. In one hand the tip-leakage vortex is far from the blade in that regime. In the other hand the ratio between the velocity of the main flow and the jet exit velocity influences the lateral position of the tip-leakage vortex. In the large gap regime the effect of the casing wall vanishes when the gap is increased and the tip-leakage vortex becomes similar to a wing-tip vortex.

\section{GLOBAL ANALYSIS OF THE TIP-LEAKAGE FLOW LOSSES}

The global losses in a flow are represented by the mass-flow average of the total pressure loss coefficient $C_{P t}^{m}$. Indeed for an incompressible flow around a fixed setup,

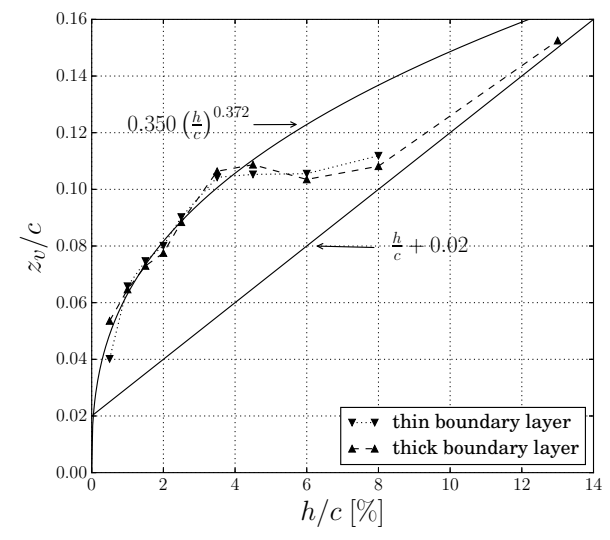

Fig. 5: Vortex center vertical position at $x / c=1.05$

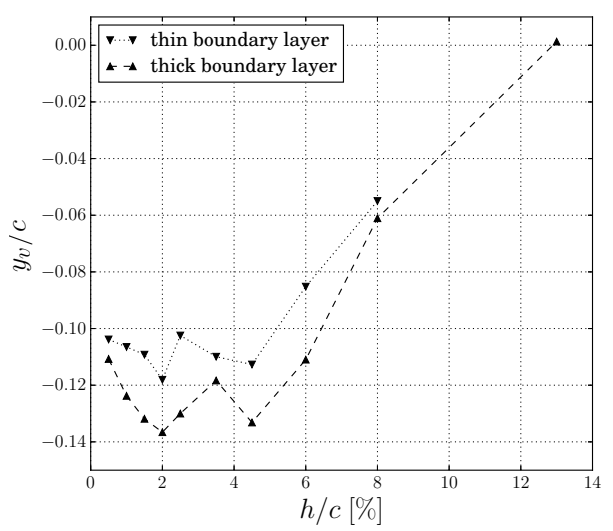

Fig. 6: Vortex center lateral position at $x / c=1.05$

equation (1) shows that $C_{P t}^{m}$ is equivalent to the sum of entropy production in a streamtube $\Sigma$ going from far upstream to the measurement plane $S_{m}$, divided by the mass-flow $\dot{m}$ through $S_{m}$.

$$
C_{P t}^{m}=\frac{\iint_{S_{m}} C_{P t} \rho u_{x} d S}{\dot{m}}=\frac{\rho T_{t \infty}}{\frac{1}{2} U_{\infty}^{2}} \frac{\iiint_{\Sigma} \vec{u} \cdot \nabla s d V}{\dot{m}}
$$

The total pressure loss $C_{P t}$ is decomposed in two terms in relation (2). For an axisymmetric vortex, it can be shown that the first term $C_{\text {vortex }}$ is proportional to the square of its circulation. Besides, as shown in figure 7 , surface averaged value of $C_{\text {vortex }}$ seems to increase with $\Gamma^{2}$. For gap heights smaller than $6.0 \%$ of chord, which corresponds to $\Gamma^{2} /\left(c U_{\infty}\right)^{2}<0.11$, the difference between the surface and mass-flow averages is small. For larger gaps, figure 9 shows that the vortex core has a significant streamwise velocity surplus, hence the deviation of the mass-flow average from the surface average. The second term $C_{\text {wake }}$ is a deficit of $u_{x}^{2}$. Thus $C_{\text {wake }}$ can be interpreted as the contribution of wakes to the total pressure losses. 


$$
C_{P t}=\underbrace{\left[\frac{P_{s \infty}-P_{s}}{\frac{1}{2} \rho U_{\infty}^{2}}-\frac{\left(u_{y}^{2}+u_{z}^{2}\right)}{U_{\infty}^{2}}\right]}_{C_{\text {vortex }}}+\underbrace{\left[1-\left(\frac{u_{x}}{U_{\infty}}\right)^{2}\right]}_{C_{\text {wake }}}
$$

The evolution of the mass-flow averaged losses with the gap height is shown in figure 8 . The total pressure loss coefficient $C_{P t}^{m}$ increases linearly for $h / c<4 \%$, then increases more slowly for bigger gaps and even decreases for $h / c=13 \%$.

This rise of $C_{P t}^{m}$ comes mainly from the vortex loss coefficient $C_{\text {vortex }}^{m}$ which seems to increase linearly with $h$ for $h / c \leq 8 \%$.

The slower augmentation of $C_{P t}^{m}$ for $h / c>4 \%$ corresponds to a decrease of the wake loss coefficient $C_{\text {wake }}^{m}$. Besides, based on figure 9 , this reduction of $C_{\text {wake }}^{m}$ is caused by the arising of a streamwise over-velocity in the vortex core which compensates the streamwise velocity deficit present in the other regions of the flow.

For $h / c=13 \%$ the coefficient $C_{\text {vortex }}^{m}$ seems to stagnate whereas $C_{\text {wake }}^{m}$ continue to decrease, hence the reduction of total pressure loss coefficient for this gap size.

Increasing the casing boundary layer thickness translates $C_{\text {wake }}^{m}$ and $C_{\text {vortex }}^{m}$ of approximately +0.027 and -0.016 respectively. As a consequence $C_{P t}^{m}$ is increased of about 0.011 , which corresponds to $8 \%$ of the smallest value of $C_{P t}^{m}$. In other words the casing boundary layer thickness has no major influence on the evolution of the wake and vortex losses with the gap height. Only the relative contributions of the vortex losses and wake losses to the total pressure losses are impacted by a thickening of the casing boundary layer.

In summary, the increase of the total pressure coefficient $C_{P t}^{m}$ with the gap height comes from the augmentation of the tip-leakage vortex circulation. Indeed it seems that the $C_{\text {vortex }}^{m}$ increases linearly with $\Gamma^{2}$. The contribution of velocity deficit $C_{\text {wake }}^{m}$ to the total pressure losses is significant for small gaps and becomes weaker for larger gaps. Changing the casing boundary layer thickness does not have a significant influence on the evolution of the loss coefficients with the gap height.

\section{THEORETICAL PREDICTION OF THE TIP- LEAKAGE VORTEX CIRCULATION}

It has previously been shown that the rise in total pressure losses is mainly attributed to the vortex contribution which seems to increase as the square of the circulation. That is why a theoretical study was performed in order to model the evolution of the tip-leakage vortex circulation $\Gamma$ with respect to gap height $h$.

Moreover, the evolution of the losses are not significantly influenced by the casing boundary layer thickness. Therefore, the casing is considered as an inviscid wall in

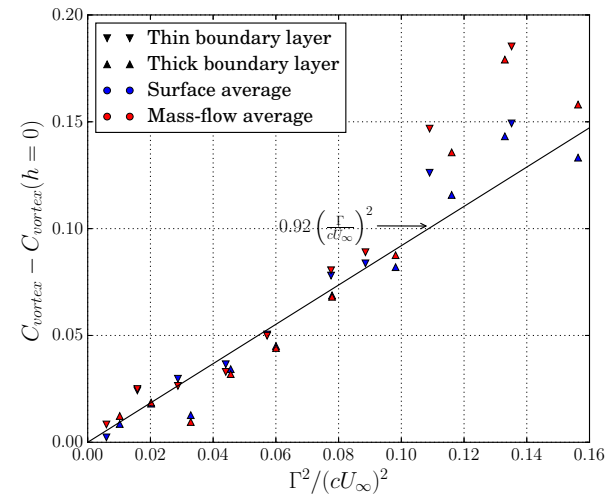

Fig. 7: Correlation between vortex losses and circulation. The value of $C_{v o r t e x}$ at $h=0$ is extrapolated from the experimental data

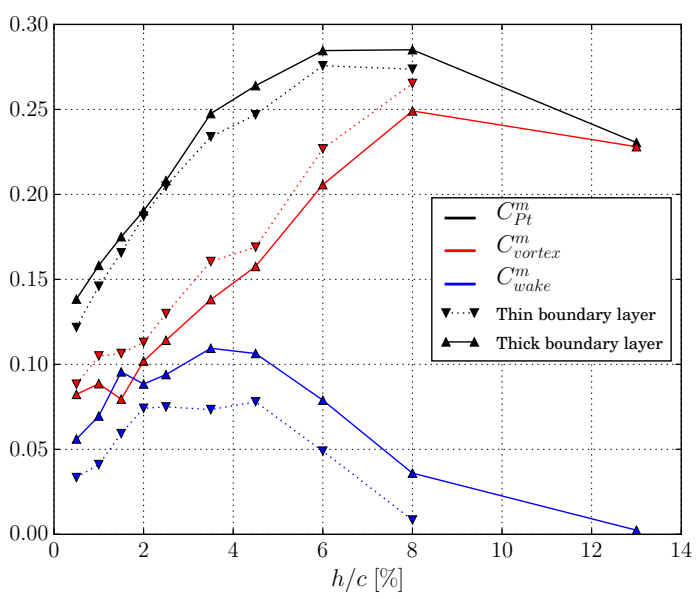

Fig. 8: Evolution of mass-flow averaged losses

this theoretical study. The casing wall then constitutes a symmetry plane of a slotted wing configuration (see figure 10) where the slot corresponds to twice the gap.

\subsection{MODELLING THE FLOW AS A JET IN CROSSFLOW}

In the small gap regime, the flow is modelled as a jet in crossflow. Jacquin [13] and Karagozian [14] reported the production of a symmetrical counter-rotating vortex pair aligned with the direction of the crossflow: the symmetry plane corresponds to the casing wall. Jacquin [13] considered an analogy with a wing wake in order to assess the jet contribution to the circulation of this vortex pair. The jet thrust is assimilated to the lift generated by a wing which span is $2 z_{v}$, the distance between the two counter-rotating vortex cores (see figure 10):

$$
\rho \overline{U_{j}^{2}} A_{j}=\rho U_{\infty} \int \Gamma \mathrm{d} z=2 \rho U_{\infty} \Gamma z_{v}
$$




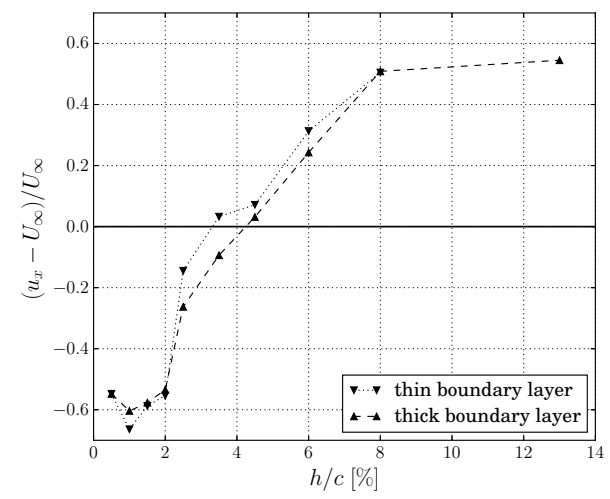

Fig. 9: Streamwise velocity in the vortex center

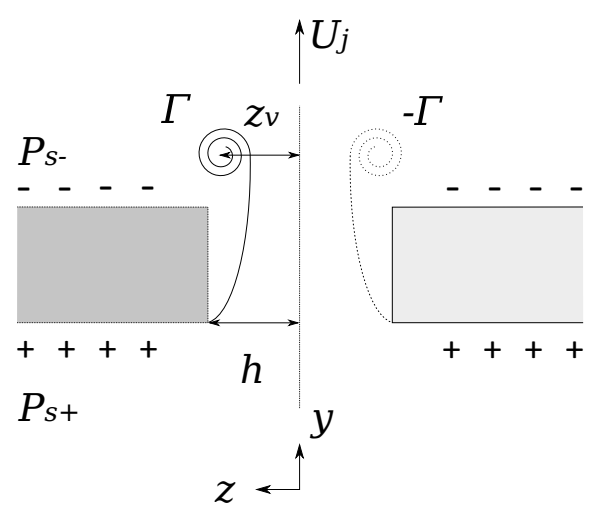

Fig. 10: The slotted wing configuration

where $A_{j}=2 h c$ is the slot area and $\overline{U_{j}^{2}}$ is the mean value of the jet velocity squared. $\Gamma$ can finally be expressed in terms of $\overline{U_{j}^{2}}$ :

$$
\frac{\Gamma}{c U_{\infty}}=\frac{h}{z_{v}} \frac{\overline{U_{j}^{2}}}{U_{\infty}^{2}}
$$

The flow entering the gap gives birth to a separation bubble and can be considered as two-dimensional [11]. Rains assumed the fluid at rest on the pressure side: $P_{s+}(\xi)$ and $P_{s^{-}}(\xi)$ are the pressure respectively on the pressure and suction side at chord position $\xi$ (see figure 10). Moore and Tilton [15] defined an overall discharge coefficient $\chi_{D}$ which accounts for the separation bubble and links the jet velocity $U_{j}(\xi)$ to the pressure difference $\Delta K_{P}(\xi)$ across the blade:

$$
\frac{U_{j}(\xi)}{U_{\infty}}=\chi_{D} \sqrt{\frac{P_{S+}(\xi)-P_{s-}(\xi)}{\frac{1}{2} \rho U_{\infty}^{2}}}=\chi_{D} \sqrt{\Delta K_{P}(\xi)}
$$

Equation (5) corresponds to a pressure loss formula in which $\chi_{D}$ is a discharge coefficient accounting for the losses inside the gap. Moreover $P_{s+}(\xi)$ and $P_{s-}(\xi)$ correspond to the pressure respectively on the pressure and suction side of a two-dimensional airfoil. The mean value of the jet velocity squared $\overline{U_{j}^{2}}$ is linked to the two-dimensional lift coefficient $C_{L}$ :

$$
\begin{aligned}
\frac{\overline{U_{j}^{2}}}{U_{\infty}^{2}} & =\chi_{D}^{2} \int_{0}^{c} \frac{P_{s+}(\xi)-P_{s-}(\xi)}{\frac{1}{2} \rho U_{\infty}^{2} c} \mathrm{~d} \xi \\
& \approx \chi_{D}^{2} C_{L}
\end{aligned}
$$

and inserted into equation (4) such that:

$$
\frac{\Gamma}{c U_{\infty}}=\frac{h}{z_{v}} \frac{\overline{U_{j}^{2}}}{U_{\infty}^{2}} \approx \frac{h}{z_{v}} \chi_{D}^{2} C_{L}
$$

As shown in figure 5 , the vortex height $z_{v}$, which varies with respect to $h$, is fitted based on experimental measurements of the position of the tip-leakage vortex:

$$
\frac{z_{v}}{c}=A\left(\frac{h}{c}\right)^{a}=0.35\left(\frac{h}{c}\right)^{0.372}
$$

where $A$ and $a$ are empirical coefficients. The discharge coefficient $\chi_{D}$ is adjusted to 0.9 in order to fit the experimental values of the circulation. This value of $\chi_{D}$ is close to the value of 0.84 obtained by Rains [11] and supported by Moore and Tilton [15].

\subsection{RESULTS AND DISCUSSION}

The evolution of the circulation of the tip-leakage vortex versus gap height is given in figure 11. For gap heights lower than $4.5 \%$ of the chord, the model is in good agreement with experimental data. For bigger gap heights, the experimental curve seems to tend towards a constant asymptotic value represented by the horizontal dashed line. This asymptotic value corresponds to the circulation of the tip vortex of an isolated wing computed with Prandtl's lifting-line theory [16].

Those results also suggest that the tip-leakage flow undergoes several regimes depending on the size of the gap: a small-gap regime which entails the generation of a jet in the main flow, a big-gap regime which corresponds to the formation of a wing-tip vortex and an intermediate regime.

Fearn and Weston [12] reported that the counterrotating vortices move away from one another as the flow marches downstream and as the ratio $\overline{U_{j}^{2}} / U_{\infty}^{2}$ increases. It suggests that parameters $A$ and $a$ introduced into the model for $z_{v}$ depend on the integration plane downstream of the blade and on $C_{L}$ according to equation (6).

\section{CONCLUSIONS}

The influence of gap height and casing boundary layer thickness on the tip-leakage flow was investigated. Velocity and total pressure were measured downstream an isolated fixed blade using a 5-hole pressure probe. 


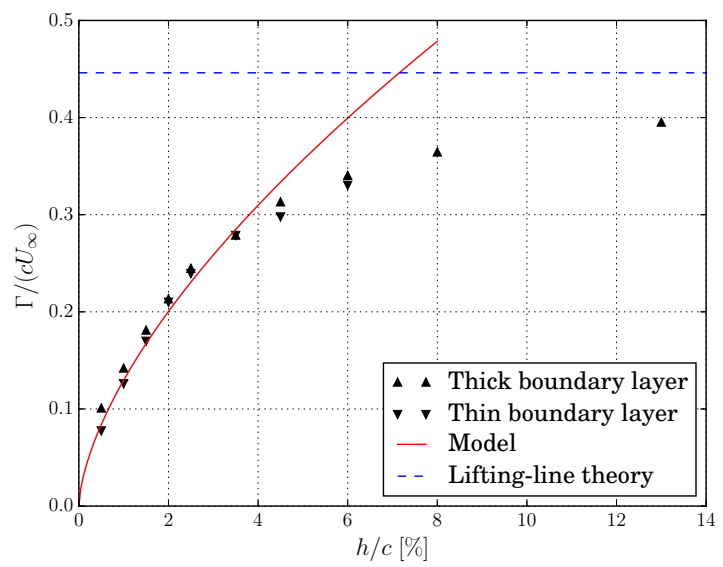

Fig. 11: Prediction of the circulation

This study reveals the existence of a small gap regime for $h / c<4.5 \%$, a large gap regime for $h / c>8 \%$ and an intermediate regime in-between. In the small gap regime the tip-leakage flow presents similarities with jets in crossflow. In the large gap regime it is comparable to a wingtip vortex. Besides a model of a jet in crossflow gives a good estimation of the tip-leakage vortex circulation for $h / c<4.0 \%$.

The total pressure loss was decomposed in a vortex loss and a wake loss. The vortex loss seems to increase with the square of the tip-leakage vortex circulation and drives the rise of total pressure losses. The wake loss is significant at small gaps and decreases for $h / c>4.5 \%$. This reduction of wake loss, which comes from the apparition of a streamwise velocity surplus in the vortex core, leads to a slower increase of the total pressure losses with the gap height.

The casing boundary layer thickness does not influence the evolution of the losses with the gap height. On the contrary a thicker boundary layer moves the tip-leakage vortex away from the blade. This effect comes from the augmentation of the ratio between the gap exit velocity and the streamwise velocity, which is associated to the penetration of a jet in a crossflow.

\section{ACKNOWLEDGEMENTS}

The present is work supported by the ANR project NumERICCS (ANR-15-CE06-0009). The simulations have been performed in the framework of the elsA threeparty agreement between AIRBUS, SAFRAN, and ONERA which are co-owners of this software.

\section{REFERENCES}

[1] Doukelis, A., Mathioudakis, K., and Papailiou, K., 1998. "The effect of tip clearance gap size and wall rotation on the performance of a high-speed annular compressor cascade". In ASME 1998 International
Gas Turbine and Aeroengine Congress and Exhibition, American Society of Mechanical Engineers.

[2] Brion, V., 2009. "Stabilité des paires de tourbillons contra-rotatifs: application au tourbillon de jeu dans les turbomachines". Theses, Ecole Polytechnique X, Oct.

[3] Muthanna, C., and Devenport, W. J., 2004. "Wake of a compressor cascade with tip gap, part 1: Mean flow and turbulence structure". AIAA Journal, 42(11), pp. 2320-2331.

[4] Flachsbart, O., 1931. "Spaltverluste an Tragflügeln". ZAMM-Journal of Applied Mathematics and Mechanics/Zeitschrift für Angewandte Mathematik und Mechanik, 11(6), pp. 411-414.

[5] Storer, J., and Cumpsty, N., 1994. "An approximate analysis and prediction method for tip clearance loss in axial compressors". Journal of Turbomachinery, 116(4), pp. 648-656.

[6] Kameier, F., and Neise, W., 1997. "Experimental study of tip clearance losses and noise in axial turbomachines and their reduction". Journal of Turbomachinery, 119(3), pp. 460-471.

[7] B. Lakshminarayana, J. H. H., 1963. Tip-clearance flow and losses for an isolated compressor blade. Technical Report ARC-R/M-3316, Aeronautical Research Council London (England).

[8] Denton, J. D., 1993. "Loss mechanisms in turbomachines". In ASME 1993 International Gas Turbine and Aeroengine Congress and Exposition, American Society of Mechanical Engineers, pp. V002T14A001-V002T14A001.

[9] Liou, M.-S., and Edwards, J., 1999. "Ausm schemes and extensions for low mach and multiphase flows". Lecture series - Von Kármán Institute for fluid dynamics, 3, pp. A1-A101.

[10] Menter, F. R., 1994. "Two-equation eddy-viscosity turbulence models for engineering applications". AIAA Journal, 32(8), pp. 1598-1605.

[11] Rains, D. A., 1954. "Tip clearance flow in axial compressors and pumps". $\mathrm{PhD}$ thesis, California Institute of Technology.

[12] Fearn, R., and Weston, R. P., 1974. "Vorticity associated with a jet in a cross flow". AIAA Journal, 12(12), pp. 1666-1671.

[13] Jacquin, L., 1994. "Phenomenological description and simplified modelling of the vortex wake issuing from a jet in a cross flow". La Recherche Aérospatiale, 2, pp. 117-133.

[14] Karagozian, A. R., 2014. "The jet in crossflow". Physics of Fluids, 26(10), p. 101303.

[15] Moore, J., and Tilton, J., 1988. "Tip leakage flow in a linear turbine cascade". Journal of Turbomachinery, 110(1), pp. 18-26.

[16] Prandtl, L., 1919. "Tragflügeltheorie. II. Mitteilung". Nachrichten von der Gesellschaft der Wissenschaften zu Göttingen, Mathematisch-Physikalische Klasse, 1919, pp. 107-137. 